the habits of the people. South African archæology intriguingly suggests culture affinities, farranging both in time and in space, and illustrates at the same time how those affinities have become more or less obscured and attenuated in the course of long migration.

At present the South African problems have to be studied to a great extent as a group of isolated phenomena, because a vast area to the north remains, archæologically, almost unexplored. Northern Rhodesia, Nyasaland, and Tanganyika Territory, when the story of their ancient cultures has been fully revealed, should throw a flood of light upon South African archæological peculiarities by furnishing evidence of the migrations routes and of the gradual changes in culture detail resulting from the dispersal southward. Farther north, in Uganda and Kenya Colony, important and suggestive work has already been carried out by Mr. E. J. Wayland and Mr. L. S. B. Leakey, the results of which have an important bearing upon the South African problems. But the full import and significance of the north and south affinities and dissimilarities will be realised when the huge intervening area has revealed its archæological secrets and contributed its data for a valuable chapter in the story of the wanderings and sojournings of migrant peoples in the course of their progress southward.

In the meantime, South Africa may well concentrate upon her local prehistoric problems, and proceed with the exploration of her past and the disentanglement of her sequence of bygone industries.

Such research into the past is surely worthy of every encouragement from the universities, and deserving of government benediction and even financial support. The material appears to be extraordinarily rich, almost inexhaustible in fact, and the deductions drawn from carefully verified data in one district can be checked and re-checked by information culled in others, so that the final summing-up should prove authoritative and highly instructive.

\title{
Tung Oil.
}

$\mathrm{T}$ UNG oil is an essential raw material of presentday varnish manufacture, and in fact its unique properties render it indispensable for certain types of varnish. Until comparatively recently, China has satisfied the world's demand for tung oil, and will, it is considered, continue to remain the chief source for some years to come. The oil is derived from two species of Aleurites, Fordii and montana, of which the former is the chief source. It was Wilson, a naturalist in western China, who in 1915, after a study of the species of Aleurites, solved the question as to the true origin of tung oil. $A$. Fordii has its habitat chiefly in western and central China, whilst $A$. montana is found more to the south. Tung oil, also termed China wood oil, was known outside China about 1760. It was first introduced into the United States in 1896, into Germany in 1897, and soon afterwards into England. Little notice of it was taken commercially in England until after the outbreak of War, when special waterresisting varnishes were required for aeroplane work. Thereafter, on the recommendation of the Raw Materials Committee of the Imperial Institute, growing experiments (Wilson having stated that he considered the trees could be grown in South Africa, East Africa, Australia, Algeria, and Morocco) were started in India, Ceylon, Malaya, Burma, Kenya, Tanganyika, Hong-Kong, and South Africa. The position of this new industry was first reviewed in a paper prepared by Dr. L. A.Jordan, of the Research Association of British Paint, Colour, and Varnish Manufacturers (Technical Paper, No. 1), published by the Association for private circulation in 1927. The work described proved of such importance and aroused such interest that the paper has been now republished, after a revision, by Dr. Jordan (Journal of the Oil and Colour Chemists Association, Vol. 12, No. 107, May 1929).

In China the tung oil trees, with reference principally to $A$. Fordii, occur abundantly and grow luxuriantly mostly in a region between Lat. $26^{\circ}$ and $34^{\circ} \mathrm{N}$., and in hilly country up to $2500 \mathrm{ft}$. in altitude, especially in the upper reaches of the Yangtze valley. A. Fordii favours the northern and $A$. montana the southern parts of the area, but there is no strongly marked division in the distribution of the species. They are ornamental trees and rapid growers producing fruit, from which the oil is extracted, in and after the third year-- though it is safest to calculate on a first crop as from the fifth year. In China the trees generally grow to $20 \mathrm{ft} .-25$ ft. in height, with a trunk of about $10 \mathrm{in}$. in diameter. But individuals are said to attain $50 \mathrm{ft} .-60 \mathrm{ft}$. with a canopy $60 \mathrm{ft}$. in diameter. The trees have a low branching habit and pruning is necessary to prevent a low straggling cover. The fruit is about the size and appearance of a russet apple. The blossoms are very sensitive to early spring frosts, and young trees, until established, are subject to frost. For other details on the manner of growth and cultivation the reader is referred to Dr. Jordan's publication. Of greater interest here is the progress made in the cultivation of this valuable tree.

As has been said, the world was dependent on China for the oil. The United States, the post-War consumption of which went up by leaps and bounds, were the first to realise the position and to take steps to obviate a total reliance on one source of supply and country. In 1914 the U.S.A. imported 61 per cent of the total Chinese export, in 1918, 77 per cent, and in 1925, 80 per cent. The American consumption is now 40,000 tons per annum. The oil is used to a considerable extent for domestic purposes in China, and the increasing world demand will encroach more and more on the stocks required for home use, which will mean that they will only be parted with at an increased price. The methods of collection and extraction of the oil in China are crude and wasteful, yet the crop is regarded as a most profitable one by the Chinese.

No. 3120, VoL. 124] 
It was these considerations which led the Americans, very soon after the War, to take up the question, added to the fact that they were reluctant to depend for their supplies on a foreign country. They began to study the possibilities of establishing a domestic industry; a period of high prices in 1923 brought the matter to a head, with the result that the American Tung Oil Corporation was formed with Mr. H. A. Gardner, the Director of the American Paint Research Institute, as vice-president and general manager. "British Paint Manufacturers stand to-day", says Dr. Jordan, "precisely where the Americans stood about 1921", The object of the Corporation has been to demonstrate primarily what could be done with tung oil trees as a crop in the hope, which has been fulfilled, of encouraging farmers to cultivate the tree on a large scale upon a commercial basis.

Judged from the manner in which this work is developing over a very wide area in the southern United States, and also in Hawaii and the American Pacific Islands, it has become evident that the farmers have responded to the efforts of the Corporation. In 1923 all the information available in America was that a few tung oil trees had been successfully grown here and there in various parts of the southern United States, the oldest of these trees being about 14 or 15 years at that time. The Corporation acquired land adjacent to the Agricultural Experimental Station of the University of Florida, and the first seedlings were planted in 1924 . By 1926, 2500 acres had been planted up, representing about 200,000 trees. Distribution of oneyear plants raised in nursery centres is made on very favourable terms to bona-fide farmers. In the autumn of 1926 the Corporation had half a million seedlings in the nurseries available for distribution. The Corporation is assisted by the U.S. Department of Commerce, and everything is being done to stimulate the independent planting of the tung oil trees. Seed is now being sold from the nurseries to large landholders, and several hundred pounds of seed were shipped in 1927 to New Zealand, Jamaica, the Virgin Islands, the Philippines, and to England for Colonial purposes. In the Report for 1928 the area under tung oil trees amounted to 4000 acres, whilst another 1000 acres was projected in Florida during 1929.

Experiments have been made as to the best machinery for crushing the seed, $30,000 \mathrm{lb}$. of seed being experimented upon in 1928. In January 1929, the first large-scale tung oil mill came into operation, capable of expressing about 50 gallons of oil per hour; this marking the commencement of activities on a commercial scale. As yet but a small percentage of the trees grown are of an age to produce fruit ; it is considered, however, that in a few years a considerable supply should become available. It is estimated that an area of 100,000 acres would be required to supply the present American demand. The quality of the American oil is said to be better than the Chinese and freer from impurities.

Turning now to the activities in this direction in the British Empire, it is apparent that they fall far short of the American. Prior to 1927 they were almost negligible. It has been stated that experiments were started in various Colonies in 1917, though the amount of available seed was small. Kenya had a record planting at 5500 feet in 1922 , seed from the trees being sent to the Imperial Institute in 1927. India carried out experiments at the Forest Research Institute at Dehra Dun. In 1924 trees of $A$. Fordii were fruiting at six years old but the seed germinated badly. The work, however, was still in an experimental stage.

The last two years have witnessed a real movement. It was in 1927 that the Research Association of British Paint, Colour, and Varnish Manufacturers took the matter up and Dr. Jordan's first pamphlet appeared, of which 600 copies were printed and widely distributed; considerable interest and enthusiasm on the subject was thereby stimulated in many parts of the Empire. The Research Association then took the step of purchasing $700 \mathrm{lb}$. of selected seed of $A$. Fordii of the 1927 American crop and distributed it to privately owned farms and estates, government agricultural stations, and forest officers over the widest possible area. The general manager of the American Tung Oil Corporation rendered invaluable help in this matter, not only with seed but also with advice; "for the American view", says Dr. Jordan, "is that beyond a certain point they must ultimately look to British Empire production to augment their own supplies ". The distribution of the seed by the Research Association was effected with the help and advice of Sir William Furse, Director of the Imperial Institute, and Dr. A. W. Hill, Director of the Royal Botanic Gardens, Kew, who heartily co-operated.

The seed was sent to middle and East and South Africa, India (Nilgiris, Malwa plateau, C.I., Bihar and Orissa, Bengal and Assam, the latter province being regarded as the most promising), Malaya, Ceylon, and Burma, where A. montana is indigenous. Seven tea estates have taken up the matter in Assam. All of them report approximately 50 per cent germination. One estate reports trees averaging $4 \mathrm{ft}$. in four months after transplanting: three reported $6 \mathrm{ft}$. trees as the rate of growth from seed in one season.

Cyprus is experimenting with the seed, and work is being carried out in the West Indies, Palestine, Australia, and New Zealand. Reports as to progress are insisted upon from all recipients of seed; as Dr. Jordan tersely puts it, " No reports-no seed ". So far the reports received are mostly favourable. It is impossible to follow Dr. Jordan further in his most valuable and interesting paper, which deals fully with culture, extraction, exports, and so forth. To show the extent of the progress achieved the following extract may be quoted: "As far as Africa is concerned, tung oil plants of our 1927 seed are now being watched everywhere from Kenya to the Cape-in Nyasaland, Tanganyika, the Rhodesias, Transvaal, Natal, and Cape Province, and in Nigeria"'. The Research Association of British Paint, Colour and Varnish Manufacturers and Dr. Jordan are to be congratulated on initiating a most valuable piece of work which appears likely to introduce a new Empire industry.

No. 3120, VoL. 124] 